\title{
High-Frequency Stimulation of the Subthalamic Nucleus Selectively Reverses Dopamine Denervation-Induced Cellular Defects in the Output Structures of the Basal Ganglia in the Rat
}

\author{
Pascal Salin, Christine Manrique, Claude Forni, and Lydia Kerkerian-Le Goff \\ Laboratoire de Neurobiologie Cellulaire et Fonctionnelle, Centre National de la Recherche Scientifique, 13402 Marseille, \\ Cedex 20, France
}

\begin{abstract}
High-frequency stimulation (HFS) of the subthalamic nucleus (STN) is now recognized as an effective treatment for advanced Parkinson's disease, but the molecular basis of its effects remains unknown. This study examined the effects of unilateral STN HFS (2 hr of continuous stimulation) in intact and hemiparkinsonian awake rats on STN neuron metabolic activity and on neurotransmitter-related gene expression in the basal ganglia, by means of in situ hybridization histochemistry and immunocytochemistry. In both intact and hemiparkinsonian rats, this stimulation was found to induce c-fos protein expression but to decrease cytochrome oxidase subunit I mRNA levels in STN neurons. STN HFS did not affect the dopamine lesion-mediated overexpression of enkephalin mRNA or the decrease in substance $P$ in the ipsilateral striatum. The lesion-induced increases in intraneuronal glutamate decarboxylase $67 \mathrm{kDa}$ isoform (GAD67) mRNA levels on the lesion side were reversed by STN HFS in the substantia nigra, partially antagonized in the entopeduncu
\end{abstract}

lar nucleus but unaffected in the globus pallidus. The stimulation did not affect neuropeptide or GAD67 mRNA levels in the side contralateral to the dopamine lesion or in intact animals. These data furnish the first evidence that STN HFS decreases the metabolic activity of STN neurons and antagonizes dopamine lesion-mediated cellular defects in the basal ganglia output structures. They provide molecular substrate to the therapeutic effects of this stimulation consistent with the current hypothesis that HFS blocks STN neuron activity. However, the differential impact of STN HFS on the effects of dopamine lesion among structures receiving direct STN inputs suggests that this stimulation may not cause simply interruption of STN outflow.

Key words: striatum; pallidum; substantia nigra; subthalamic nucleus; glutamate decarboxylase; in situ hybridization; Parkinson's disease; deep brain stimulation
The subthalamic nucleus (STN) is now recognized as the anatomical target of choice for the neurosurgical treatment of advanced Parkinson's disease (PD). The rationale for targeting the STN for neurosurgery in PD patients came from experimental evidence showing that the loss of dopaminergic nigral neurons in PD leads, through complex changes in cellular interactions in the basal ganglia circuitry, to changes in the firing rate and pattern of STN neurons, suggesting overactivity of this nucleus (Miller and DeLong, 1987; Hollerman and Grace, 1992; Bergman et al., 1994; Hassani et al., 1996). Therefore, abnormal activity of the STN, which sends glutamatergic excitatory projections to the basal ganglia output structures, represented by the substantia nigra pars reticulata $(\mathrm{SNr})$ and the internal globus pallidus also termed entopeduncular nucleus (EP), has been thought to play a pivotal role in the expression of PD symptoms. Accordingly, lesioning the STN has been reported to normalize the metabolic activity as well as the firing rate and pattern of neurons in the SNr and EP (Burbaud et al., 1995; Blandini et al., 1997), to block changes in

\footnotetext{
Received XXX; revised Feb. 22, 2002; accepted March 20, 2002.

This work was supported by grants from the Centre National de la Recherche Scientifique and the European Community (contract QLK6-1999-02173, Fifth Programme Cadre de Recherche et de Développement Technologique). We are grateful to Dr. E. Hirsch and to Dr. G. Orieux for providing us with the cytochrome oxidase subunit I riboprobe and for helpful discussion.

Correspondence should be addressed to Lydia Kerkerian-Le Goff, Laboratoire de Neurobiologie Cellulaire et Fonctionnelle, Centre National de la Recherche Scientifique, 31 chemin Joseph Aiguier, 13402 Marseille Cedex 20, France. E-mail: kerkeria@Incf.cnrs-mrs.fr.

Copyright (C) 2002 Society for Neuroscience $\quad 0270-6474 / 02 / 225137-12 \$ 15.00 / 0$
}

neurotransmitter-related gene expression resulting from dopamine denervation in basal ganglia structures (Delfs et al., 1995; Guridi et al., 1996) and to alleviate parkinsonian motor deficits (Bergman et al., 1990; Aziz et al., 1991; Alvarez et al., 2001). The high-frequency stimulation (HFS) procedure, referred to as deepbrain stimulation, has been developed in the last decade as an alternative to the ablative surgery, the targeted structure being initially the ventral intermediate thalamic nucleus to replace thalamothomy in the treatment of tremor (Benabid et al., 1987, 1991). Since 1993, evidence has been accumulated that HFS of the STN alleviates all the cardinal motor symptoms of PD, in both experimental animals and humans, and drastically reduces daily levodopa requirements and dyskinesias (Benazzouz et al., 1993; Pollak et al., 1993; Limousin et al., 1995; Benabid et al., 2000; Krause et al., 2001). The observation that HFS of the STN mostly simulates the STN lesion effects, as reported for other surgical targets, has suggested that this stimulation may act by inactivating the STN and subsequently reducing its excitatory influence onto the basal ganglia output structures. In keeping with this hypothesis, electrophysiological recordings in rats have shown that STN HFS decreases neuron activity in both the STN and the basal ganglia output structures (Benazzouz et al., 1995, 2000). However, to date, whether or not the therapeutic effects of STN HFS are underlain by reversal of the molecular defects resulting from dopamine denervation in the basal ganglia structures remains unknown.

This study was thus aimed at examining the impact of STN HFS in intact and hemiparkinsonian freely moving rats on mRNA levels of enkephalin and substance $\mathrm{P}$ in the striatum, as 
markers of the striatopallidal and striatonigral neurons, respectively, and of glutamate decarboxylase $67 \mathrm{kDa}$ isoform (GAD67) as a marker of GABA neuron activity in the external globus pallidus (GP), EP, and $\mathrm{SNr}$, by in situ hybridization histochemistry. In parallel, the reactivity of STN neurons to HFS was investigated by means of c-fos immunocytochemistry and cytochrome oxidase subunit I (CoI) mRNA detection.

\section{MATERIALS AND METHODS}

Experiments were performed on male adult Wistar rats (240-260 gm at the time of surgery; from Iffa Credo, L'arbresle, France). Animals were housed three per cage and maintained on a $12 \mathrm{hr}$ light/dark cycle at a constant temperature $\left(21 \pm 1^{\circ} \mathrm{C}\right)$ with ad libitum access to food and water. The experimental protocols, involving animals and their care, strictly conformed to the guidelines of the French Agriculture and Forestry Ministry (decree 87-848).

Surgery. Surgery was performed under chloral hydrate anesthesia (250 $\mathrm{mg} / \mathrm{kg}$, i.p.). Thirteen animals, pretreated with desipramine $(25 \mathrm{mg} / \mathrm{kg}$, s.c.) to protect noradrenergic neurons, received a unilateral injection of $12 \mu \mathrm{g}$ of 6-hydroxydopamine (6-OHDA; Sigma, St. Quentin-Fallavier, France) dissolved in $6 \mu \mathrm{l}$ of $0.9 \%$ sterile $\mathrm{NaCl}$ containing $0.1 \%$ of ascorbic acid, at the rate of $1 \mu \mathrm{l} / \mathrm{min}$ in the left substantia nigra. The stereotaxic coordinates of the injection site were: anterior (A), $-5.2 \mathrm{~mm}$ and lateral (L), $2.15 \mathrm{~mm}$ from bregma; dorsoventral (DV), $-7.6 \mathrm{~mm}$ from the skull, with the incisor bar at $3.3 \mathrm{~mm}$ below the interaural plane according to the stereotaxic atlas of Paxinos and Watson (1986).

Eight of these animals and six other rats without 6-OHDA injection were implanted unilaterally with a bipolar electrode formed by two stainless steel wires insulated with polyimide up to the exposed ends (diameter of each wire: $250 \mu \mathrm{m}$ insulated, $200 \mu \mathrm{m}$ bare; from Phymep, Paris, France) and closely twisted together. The electrode was implanted so that exposed ends are placed just above the STN to minimize mechanical damage to the structure. Indeed with the type of electrode used, the electrical field is expected (according to previous testing in egg white) to be limited to the tip of the electrode and to diffuse below. The stereotaxic coordinates from bregma using the rat brain atlas from Paxinos and Watson (1986) were: A, $-3.8 \mathrm{~mm}$; L, $2.5 \mathrm{~mm}$; DV, $-7.8 \mathrm{~mm}$ (from the skull). A group of three or four anesthetized but unoperated animals was used as control.

High-frequency stimulation. HFS was applied for $2 \mathrm{hr}$ after a 15-17 d recovery period. The objective was to investigate the possible early molecular changes mediated by STN HFS, knowing that such a stimulation in PD patients has immediate beneficial effects on PD motor symptoms. The stimulation duration was determined on the basis of previous microdialysis studies by Windels et al. (2000) in rats showing that STN HFS for $1 \mathrm{hr}$ is sufficient for inducing significant change in extracellular glutamate levels in main STN targets (GP and SNr), but that this effect develops slowly during the stimulation period. We then assume that a $2 \mathrm{hr}$ stimulation period should be a minimum to produce postsynaptic effects on gene expression. Stimuli were delivered by a pulse generator-stimulator and stimulus isolation unit (P2MP, Marseille, France) that gave rectangular pulses. The frequency was set at $130 \mathrm{~Hz}$ all over the stimulation period for all the stimulated animals. Within the first $5 \mathrm{~min}$ of stimulation, the behavioral effects of increasing the stimulation intensity from 0 to $500 \mu \mathrm{A}$ were examined in individual animals. Because slight increases in pulse width were observed in preliminary experiments to allow important reduction in intensity to induce the same behavior, fine adjustment in pulse width between 90 and $110 \mu \mathrm{A}$ was also done during this period to minimize the total energy delivered. Both parameters were then set for the $2 \mathrm{hr}$ of stimulation at values just below the threshold of the dyskinetic movement of the contralateral forepaw. Animals were killed by decapitation immediately after turning off the stimulation.

Tissue preparation. The brains were removed quickly, frozen in dry ice, and kept at $-80^{\circ} \mathrm{C}$ until cryostat sectioning. Coronal $10-\mu \mathrm{m}$-thick tissue sections were cut at $-20^{\circ} \mathrm{C}$, at the level of the striatum [rostral striatum: between interaural coordinates A, 9.2-10.2 mm based on the stereotaxic atlas of Paxinos and Watson (1986)], GP (A, 8.2-7.2 mm), EP (A, 6.7-5.7), SNr (A, 4.2-3.2), and STN (A, 5.4-4.7) and thaw mounted onto SuperFrost plus glass slides (Fisher Scientific, Elancourt, France). Tissue sections were stored at $-80^{\circ} \mathrm{C}$ until specific treatment.

Histological staining and ${ }^{3} \mathrm{H}$-mazindol binding experiments. The location of the electrode was examined on cresyl violet-stained sections. The loss of dopamine terminals in the striatum was assessed as an index of the dopamine lesion extent by analysis of ${ }^{3} \mathrm{H}$-mazindol binding to dopamine uptake sites, as previously described (Salin et al., 1996). Briefly, brain sections were air-dried and rinsed for $5 \mathrm{~min}$ in $50 \mathrm{~mm}$ Tris buffer with 120 $\mathrm{mm} \mathrm{NaCl}$ and $5 \mathrm{~mm} \mathrm{KCl}$. They were then incubated for $40 \mathrm{~min}$ with 15 nM ${ }^{3} \mathrm{H}$-mazindol (NEN Life Science Products, Boston, MA) in $50 \mathrm{~mm}$ Tris buffer with $300 \mathrm{~mm} \mathrm{NaCl}$ and $5 \mathrm{~mm} \mathrm{KCl}$ added with $0.3 \mathrm{~mm}$ desipramine to block the noradrenaline uptake sites. Sections were rinsed twice for $3 \mathrm{~min}$ in the Tris incubation buffer and for $10 \mathrm{sec}$ in distilled water and were air-dried. ${ }^{3} \mathrm{H}$-sensitive Hyperfilm photographic film (Amersham Pharmacia, Orsay, France) were apposed to the slides in x-ray cassettes and exposed at room temperature for $15 \mathrm{~d}$. Animals showing misplaced electrode or a reduction of $<85 \%$ in ${ }^{3} \mathrm{H}$-mazindol binding were discarded (one with the dopamine lesion alone, two with the lesion and STN HFS). All the following morphological experiments were then performed as a full sequence in each selected rat from the different experimental groups.

C-fos immunocytochemistry. Sections were post-fixed for $15 \mathrm{~min}$ in 0.12 M PBS, pH 7.4, containing 4\% paraformaldehyde. After several rinses in PBS, sections were preincubated three times for 5 min in PBS containing $1 \%$ hydrogen peroxide, then for $30 \mathrm{~min}$ in $10 \%$ BSA and $0.25 \%$ Triton X -100 . Thereafter, sections were incubated overnight at $4{ }^{\circ} \mathrm{C}$ with a polyclonal rabbit anti-c-fos antiserum (1:4000 in PBS containing 2\% BSA; Santa Cruz Biotechnology, Santa Cruz, CA), then for $1 \mathrm{hr}$ in biotinylated goat anti-rabbit IgG secondary antibody (1:200 in PBS containing 2\% BSA; from Vector Laboratories, Burlingame, CA). After several rinses $(3 \times 5 \mathrm{~min}$ in PBS with $2 \%$ BSA and $3 \times 5$ min in PBS with $5 \%$ BSA $)$, the sections were processed for immunodetection through the following incubations: $45 \mathrm{~min}$ in an avidin-biotin-peroxidase complex (Elite ABC kit, Vectastain; Vector Laboratories), $10 \mathrm{~min}$ in a solution containing $0.025 \%$ diaminobenzidine, and $2-5 \mathrm{~min}$ in the diaminobenzidine solution added with $0.03 \%$ hydrogen peroxide.

In situ hybridization. Radiolabeled antisense synthetic DNA probes (43-48 mer) were used for preprotachykinin (substance P), preproenkephalin A (enkephalin), and GAD67 in situ hybridization, as previously described (Liévens et al., 1997). Briefly, the oligoprobes were $3^{\prime}$ endlabeled by terminal deoxynucleotide transferase (Roche, Meylan, France) with ${ }^{35} \mathrm{~S}-\mathrm{dATP}(1300 \mathrm{Ci} / \mathrm{mmol}$; NEN Life Science Products). The probes were then purified from unincorporated nucleotides on sephadex mini spin columns (Roche). A radiolabeled antisense RNA probe was used for CoI mRNA detection. The cDNA, corresponding to nucleotides 5308-6218 within the gene coding for CoI of the rat mitochondrial genome (EMBO databank, ref MIRNXX) was generously provided by Dr. E. Hirsch (Vila et al., 2000). The antisense RNA probe was transcribed from $1 \mu \mathrm{g}$ of linearized plasmid containing the cDNA fragment, using a T3 polymerase, $2.5 \mathrm{mM}{ }^{35} \mathrm{~S}$-UTP $(1200 \mathrm{Ci} / \mathrm{mmol})$ with ATP, CTP, and GTP in excess.

Slide-mounted sections were postfixed for $5 \mathrm{~min}$ in $3 \%$ paraformaldehyde, incubated for $30 \mathrm{~min}$ in prehybridization buffer $(2 \times$ SSC and $1 \times$ Denhardt's solution) and acetylated for $10 \mathrm{~min}$ with $0.25 \%$ acetic anhydride in $0.1 \mathrm{M}$ triethanolamine. Then, the tissue was treated for $30 \mathrm{~min}$ with $0.1 \mathrm{M}$ Tris-glycine, dehydrated, and air dried. When using oligoprobes, each section was covered with $35 \mu \mathrm{l}$ of hybridization buffer $(50 \%$ formamide, $1 \times$ Denhardt's, $1 \%$ yeast tRNA, $1 \%$ sheared salmon sperm DNA, $10 \%$ dextran sulfate, $4 \times$ SSC) containing $20 \mathrm{nmol}$ of radiolabeled probe $(\sim 400,000 \mathrm{cpm})$ and incubated for $12-14 \mathrm{hr}$ at $42^{\circ} \mathrm{C}$ in humid chambers. After hybridization, the sections were washed sequentially in $1 \times \mathrm{SSC}$ for $1 \mathrm{hr}$ at room temperature, $1 \times \mathrm{SSC}$ for $1 \mathrm{hr}$ at $42^{\circ} \mathrm{C}$, and $0.1 \times$ SSC for $1 \mathrm{hr}$ at $42^{\circ} \mathrm{C}$. For riboprobe, each section was covered with $20 \mathrm{ml}$ of the same hybridization buffer containing $6 \mathrm{ng}$ of CoI probe $(\sim 2.5 \times$ $\left.10^{-6} \mathrm{cpm}\right)$ and incubated for $4 \mathrm{hr}$ at $50^{\circ} \mathrm{C}$. Posthybridation treatments included washes at $52^{\circ} \mathrm{C}$ with $50 \%$ formamide in $2 \times \mathrm{SSC}$ and incubation with RNase A $(100 \mathrm{mg} / \mathrm{ml})$ in $2 \times \mathrm{SSC}$ at $37^{\circ} \mathrm{C}$ for $30 \mathrm{~min}$. In both cases, the sections were then dehydrated and apposed to Kodak BioMax MR (Eastman Kodak, Rochester, NY) films in light-tight cassettes for 2-10 d. Sections processed for cellular analysis were thereafter coated with Amersham LM1 autoradiographic emulsion and exposed at $4^{\circ} \mathrm{C}$ for $5 \mathrm{hr}$ for $\mathrm{CoI}$ and for 10-15 d for GAD67 mRNA detection. Exposed slides were developed in Kodak D-19 for 4 min at $13^{\circ} \mathrm{C}$ and counterstained with toluidine blue. Brain sections from the four experimental groups of animals (three sections per individual) were run in the same in situ hybridization session.

Data analysis. The levels of striatal enkephalin and substance P mRNA labeling were quantified by digitized image analysis from film autoradiograms using a BIOCOM analysis system (Densirag; BIOCOM, Les Ulis, France). Gray levels were converted to optical densities (OD) using 

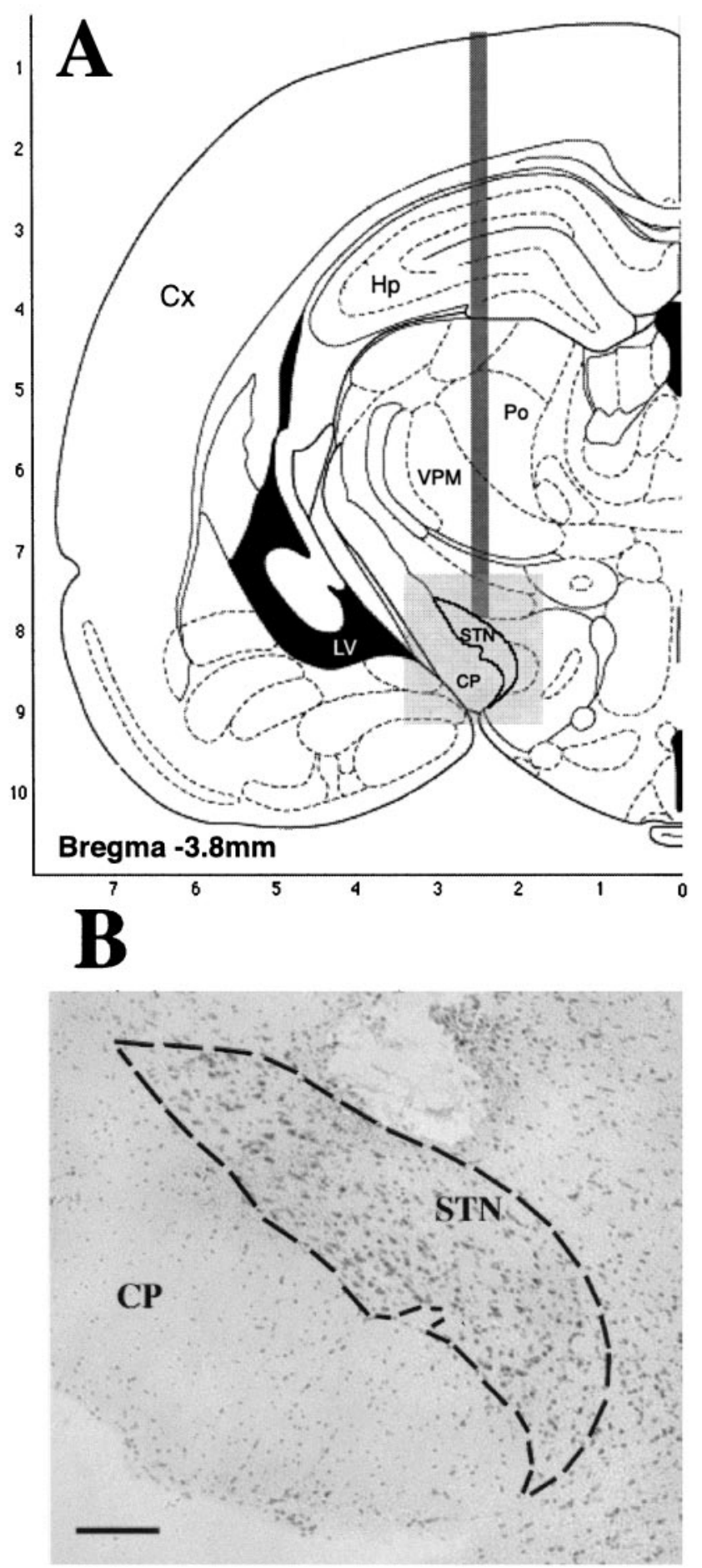

Figure 1. Schematic diagram $(A)$ (adapted from the stereotaxic atlas of Paxinos and Watson, 1986) and photomicrograph of a cresyl violetstained section $(B)$ at subthalamic nucleus level ( $S T N$; delineated by dotted lines in $B$ ) illustrating the location of the electrode. $C P$, Cerebral peduncle; $C x$, cerebral cortex; $H p$, hippocampus; $L V$, lateral ventricle; $P o$, posterior thalamic nuclear group; $V P M$, ventral-posteromedial thalamic nucleus. Scale bar, $150 \mu \mathrm{m}$.

external standards (calibrated density step tablet; Kodak). The mean OD value was determined from three sections per animal after subtracting the background signal measured on each section by scanning a cortex area that is known to lack substance $\mathrm{P}$ and enkephalin neurons. Analysis of GAD67 mRNA labeling in GP, EP, and SNr and of CoI mRNA in the
A
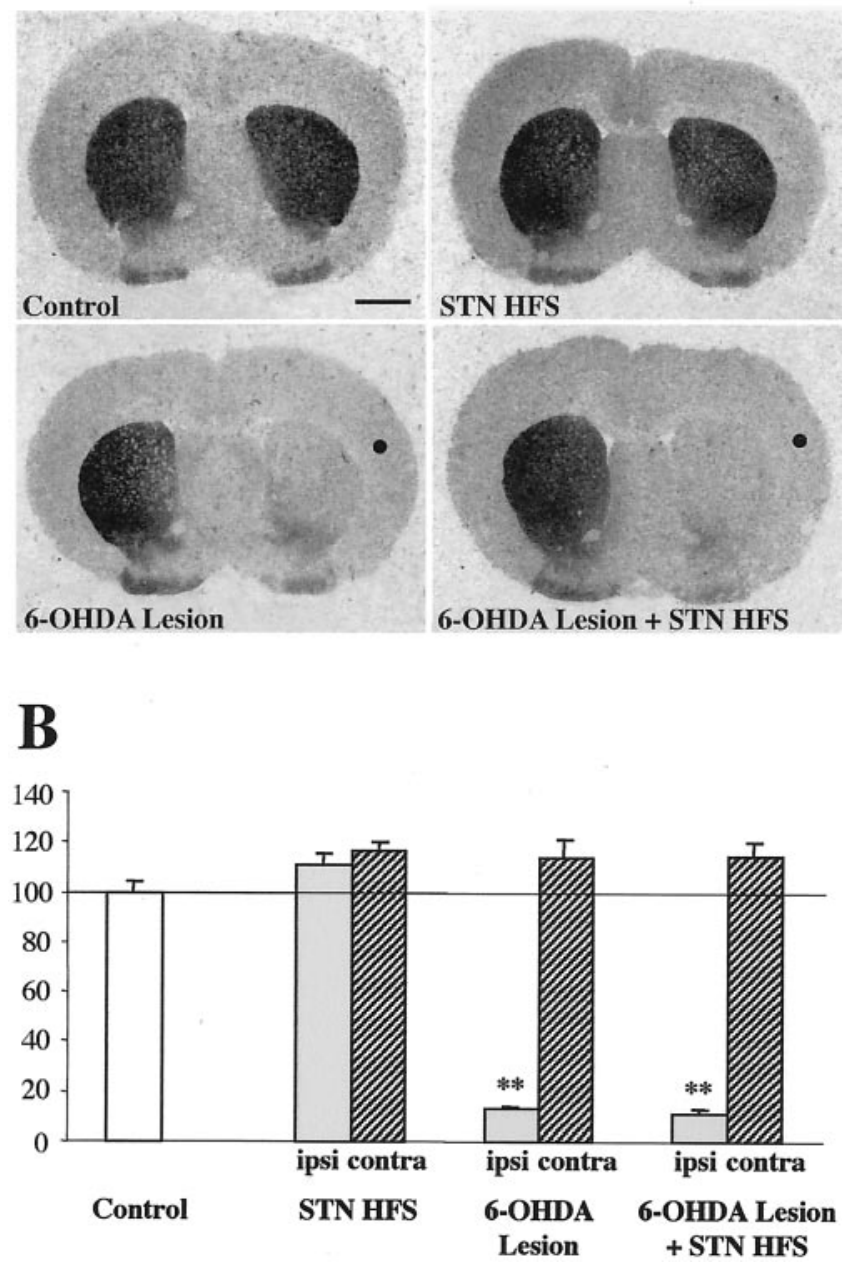

Figure 2. Digitized autoradiographic images $(A)$ and quantitative analysis $(B)$ showing the effects of separate or combined unilateral 6-hydroxydopamine lesion and high-frequency stimulation of the subthalamic nucleus on striatal ${ }^{3} \mathrm{H}$-mazindol binding to dopamine uptake sites. The data presented in the graphs are the means \pm SEM of the optical density values determined from $n$ animals per condition and are expressed as percentages of control. Statistical comparisons are performed using a one-way ANOVA followed by Scheffé's test. Scale bar, $2 \mathrm{~mm}$. ${ }^{\bullet}$ Side ipsilateral to surgery; ${ }^{* *} p<0.01$ compared with control values.

STN was done at cellular level on emulsion-coated sections. Sections were observed under dark-field epi-illumination with an immersion $20 \times$ objective of a microscope connected to a $\mathrm{COHU}$ camera, and the digitized images were transferred to the screen of a video monitor with a resulting magnification of $1000 \times$. Using the Visioscan image analysis system (BIOCOM), the number of silver grains per cell was estimated under polarized light by measuring OD with respect to a standard curve of a defined number of silver grains. In the present experiments, autoradiographic background was extremely low, so that the corresponding value was not subtracted. A random sample of 30-50 labeled neurons ( $>5$ grains) per section and per brain side was quantified in three sections from each animal, and the mean number of silver grains per neuron was determined. The data from the $\mathrm{n}$ animals per condition were then averaged $(n=$ 3-4 control; four 6-OHDA lesioned, six stimulated, and six lesioned and stimulated animals) and expressed as means \pm SEM. Results were presented as percentage of the corresponding mean control value.

Statistical comparisons were performed for each anatomical region using a one-way ANOVA followed by Scheffé's test for multiple group comparison. A significance of $p<0.05$ was required for rejection of the null hypothesis. 

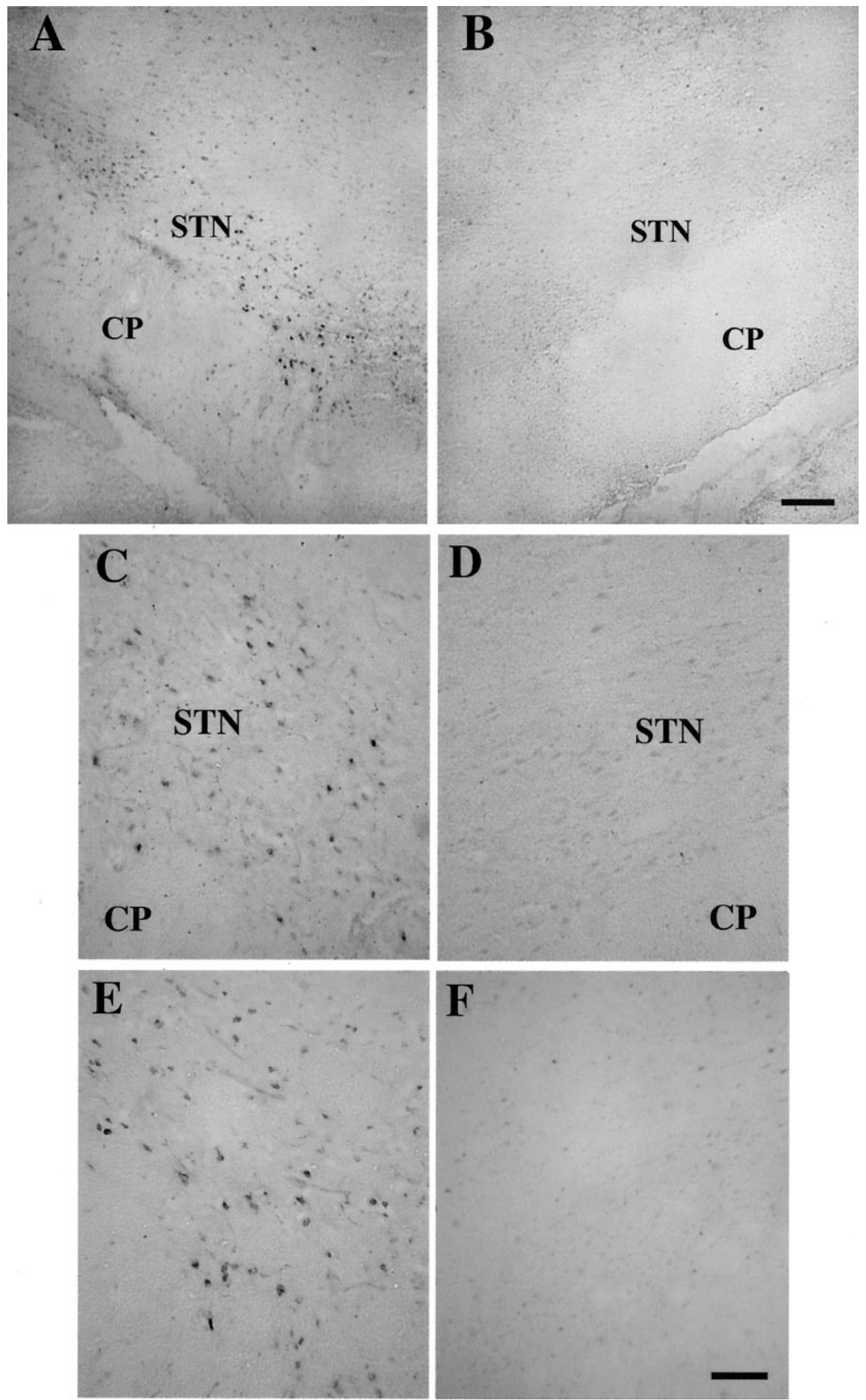

Figure 3. Effects of unilateral high-frequency stimulation of the subthalamic nucleus $(S T N)$ on c-fos immunostaining. $A$, $B$, Photomicrographs illustrating c-fos immunolabeling in the STN on the stimulated $(A)$ and contralateral $(B)$ sides in an hemiparkinsonian rat. Scale bar, $180 \mu \mathrm{m}$. $C-F$, Higher magnification photomicrographs from intact $(C, D)$ and hemiparkinsonian $(E, F)$ rats on the stimulated $(C, E)$ and contralateral $(D, F)$ sides in the same sections. Scale bar, $70 \mu \mathrm{m}$. $C P$, Cerebral peduncle. 


\section{RESULTS}

\section{Behavioral observations}

Animals with the lesion had an ipsilateral bias in the head position, and some of them show a weak tendency to ipsilateral rotation. Progressively increasing the stimulation intensity was observed to induce a similar sequence in intact and lesioned animals. It was characterized first by orofacial dyskinetic movements, thereafter dyskinetic movements of the contralateral forepaw (preceded in lesioned animals by a normalization of the ipsilateral bias in head position) followed by a strong contralateral bias in the head position, and finally contralateral rotation. However, the stimulation intensity required to produce these effects was observed to be significantly higher in lesioned versus intact stimulated rats, indicating lower sensitivity to the stimulation. For instance, to be just below the threshold of the dyskinetic movement of the contralateral forepaw, the stimulation parameters were: intensity, $400 \pm 20$ versus $292 \pm 44 \mu \mathrm{A}$; pulse width, $108 \pm 4.1$ versus $93 \pm 5.2 \mu \mathrm{sec}$ ).

\section{Control of the electrode location and of the dopamine lesion extent}

Figure 1 illustrates the location of the stimulation electrode, which was just above the STN, in the selected animals. No major tissue damage was observed in the structure.

The animals with or without STN HFS that received a unilateral injection of 6-OHDA showed an almost complete loss of ${ }^{3} \mathrm{H}$-mazindol binding in the ipsilateral striatum (Fig. 2). No significant change in striatal ${ }^{3} \mathrm{H}$-mazindol binding was found in the side contralateral to the lesion or in both brain sides in intact rats with STN HFS.

\section{c-fos immunolabeling and Col gene expression in the subthalamic nucleus}

In control and 6-OHDA lesioned rats without STN HFS, virtually no c-fos immunoreactivity was observed at STN level. HFS induced abundant c-fos expression within the STN on the stimulation side, both in intact rats and in animals with the dopamine lesion (Fig. 3). No contralateral induction was observed (Fig. 3).

Regarding CoI mRNA expression in the STN (Fig. 4), the levels of intraneuronal labeling did not significantly differ from control values in animals with the dopamine lesion alone, but were reduced on the stimulation side, selectively, in both intact and lesioned rats with STN HFS. It can be noted, however, that there is a slight although not significant decrease in the contralateral STN after STN HFS alone or dopamine lesion alone, which is no more observed in animals with the lesion and STN HFS.

\section{Enkephalin and substance P mRNAs in the striatum}

STN HFS in intact rats did not affect striatal enkephalin (Fig. 5) or substance P (Fig. 6) mRNA levels whatever the brain side examined. Unilateral dopamine lesion was shown, in agreement with previous reports (Gerfen et al., 1991; Delfs at al., 1995; Hajji et al., 1996), to result in increased enkephalin and decreased substance P mRNA levels in the striatum ipsilateral to the lesion side, in the absence of contralateral changes. The dopamine lesion-mediated changes were unaffected by STN HFS. No significant differences in striatal mRNA levels of either enkephalin (Fig. 5) or substance P (Fig. 6) were detected between animals with the dopamine lesion alone and those with the lesion and STN HFS, whatever the brain side examined.
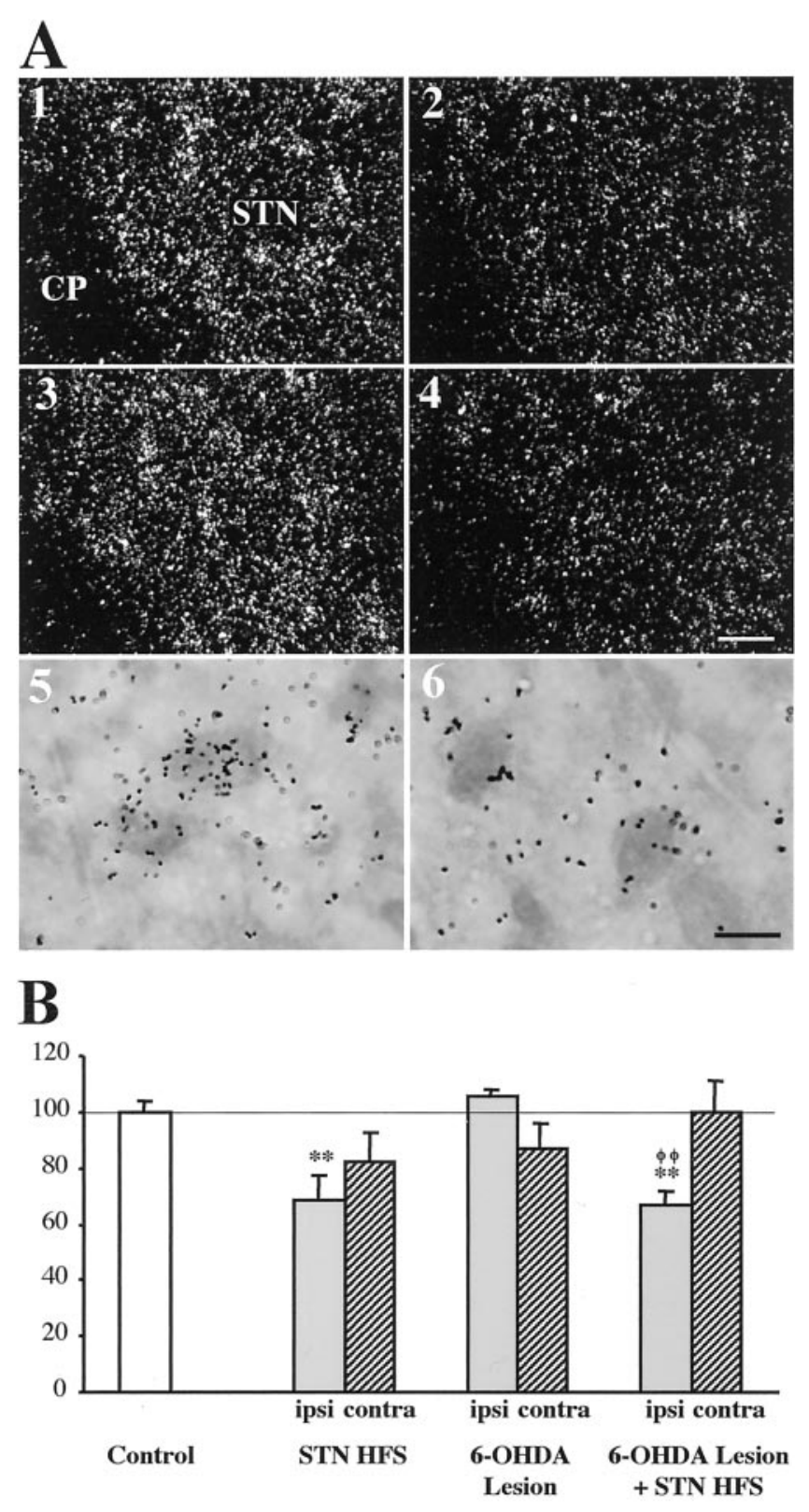

Figure 4. Photomicrographs $(A)$ and quantitative analysis $(B)$ showing the effects of unilateral HFS of the subthalamic nucleus (STN) on CoI mRNA levels in the STN. Sections were processed for in situ hybridization with ${ }^{35} \mathrm{~S}$-radiolabeled CoI cRNA probe and emulsion autoradiography. $A 1-A 4$, Photomicrographs taken under dark-field epi-illumination showing the expression of CoI mRNA in the STN of a control animal (1), an animal with STN HFS alone (2), an animal with the dopamine lesion alone (3), and an animal with the dopamine lesion and STN HFS (4). Only the STN on the lesion or stimulation side is illustrated. $C P$, Cerebral peduncle. Scale bar, $50 \mu \mathrm{m}$. $A 5, A 6$, Bright-field photomicrographs at higher magnification $(1000 \times)$ of toluidine blue-counterstained sections illustrating the decrease in the number of silver grains per labeled neuron in the ipsilateral STN after STN HFS in an animal with the dopamine lesion (6) as compared with control labeling (5). Scale bar, $10 \mu \mathrm{m}$. $B$, Histograms representing the mean of silver grain number per labeled neuron on the ipsilateral and contralateral sides in the different conditions. Quantitative analysis was performed under dark-field epi-illumination at a final magnification of $1000 \times$ using the Visioscan image analysis system (BIOCOM) as described in Material and Methods. The data are expressed as percentage \pm SEM of the corresponding controls. Statistical comparisons versus control values are performed using a one-way ANOVA followed by Scheffé's test. ${ }^{* *} p<0.01$ compared with control values; ${ }^{\phi \phi} p<0.01$ compared with values obtained in animals with the dopamine lesion alone. 
$\mathbf{A}$
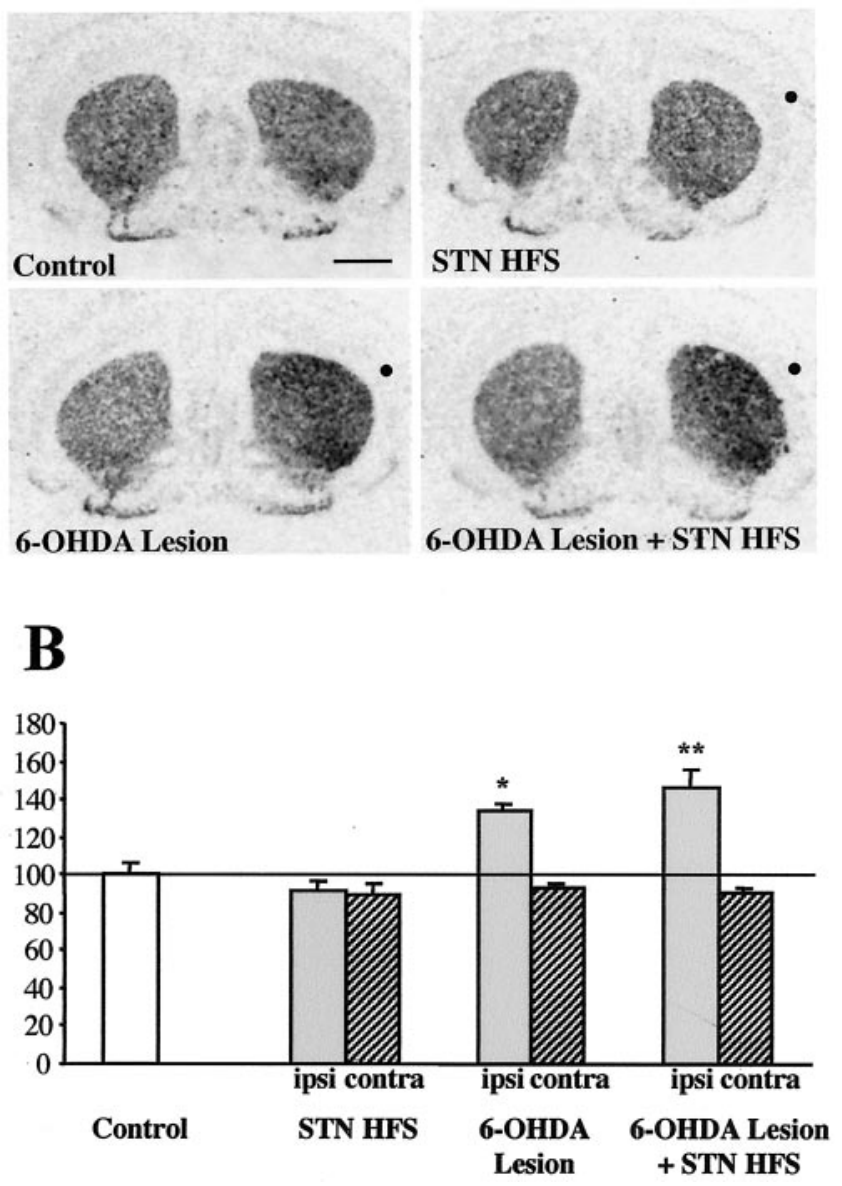

Figure 5. Digitized autoradiographic images $(A)$ and quantitative analysis $(B)$ showing the effects of separate or combined unilateral highfrequency stimulation of the subthalamic nucleus and 6-hydroxydopamine lesion of nigral neurons on striatal enkephalin mRNA expression. The data presented in the graphs are the means \pm SEM of the optical density values determined from $n$ animals per condition and are expressed as percentages of control. Statistical comparisons are performed using a one-way ANOVA followed by Scheffé's test. Scale bar, $2 \mathrm{~mm}$. ${ }^{\bullet}$ Side ipsilateral to surgery; ${ }^{*} p<0.05$ and ${ }^{*} p<0.01$ compared with control values.

\section{GAD67 mRNA levels in the globus pallidus}

STN HFS in intact rats did not significantly modify the levels of intraneuronal GAD67 mRNA labeling in the GP (Fig. 7; see Fig. 10) ipsilateral or contralateral to the stimulation side. As reported previously (Kincaid et al., 1992; Soghomonian and Chesselet, 1992; Vila et al., 1999), unilateral dopamine lesion induced a marked increase in GAD 67 mRNA levels in neurons of the ipsilateral GP, confirmed by the shift to the right of the frequency distribution of labeling per cell, without affecting contralateral labeling. The dopamine lesion-induced increase was not significantly modified by STN HFS.

\section{GAD67 mRNA levels in the entopeduncular nucleus}

STN-HFS alone did not significantly change the intraneuronal levels of GAD 67 gene expression in the EP (Fig. 8; see Fig. 10) of both brain sides. In animals with the unilateral dopamine lesion alone, intraneuronal GAD67 mRNA levels were strongly increased in the EP ipsilateral to the lesion but unaffected in the contralateral EP. Frequency distribution analysis confirmed this
A
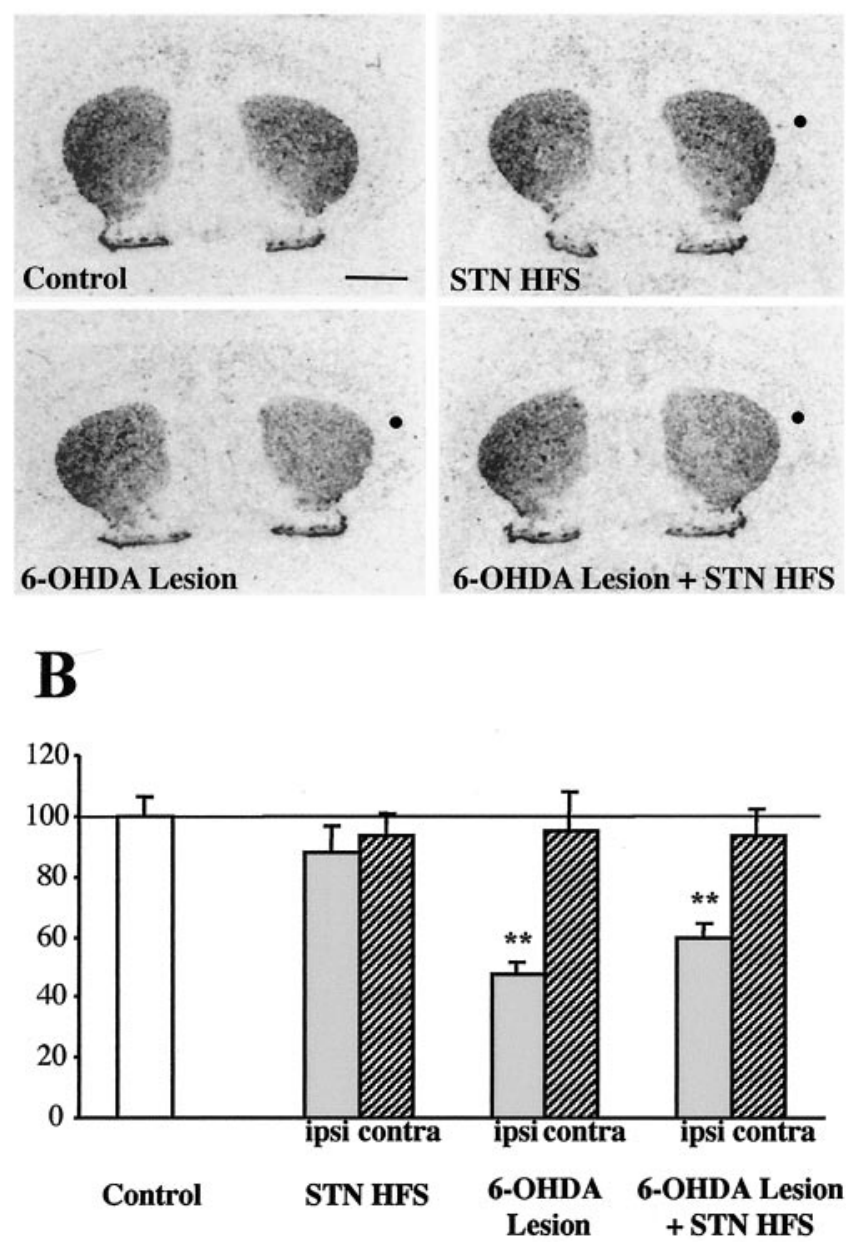

Figure 6. Digitized autoradiographic images $(A)$ and quantitative analysis $(B)$ showing the effects of separate or combined unilateral highfrequency stimulation of the subthalamic nucleus and 6-hydroxydopamine lesion of nigral neurons on striatal substance P mRNA expression. The data presented in the graphs are the means \pm SEM of the optical density values determined from $n$ animals per condition and are expressed as percentages of control. Statistical comparisons are performed using a one-way ANOVA followed by Scheffé's test. Scale bar, $2 \mathrm{~mm}$. 'Side ipsilateral to surgery; ${ }^{* *} p<0.01$ compared with control values.

increase by showing a shift toward the right of the histogram compared with controls. The dopamine lesion-induced ipsilateral increase in GAD67 mRNA levels was reduced, but not abolished, by STN HFS. For instance, the mean level of labeling per cell in animals with the dopamine lesion and STN HFS was significantly lower than in animals with the dopamine lesion alone $(-19 \%)$, but remained increased compared with controls. No change was observed in the contralateral EP.

\section{GAD67 mRNA levels in the substantia nigra pars reticulata}

GAD67 mRNA expression in SNr (Figs. 9, 10) neurons was not affected by STN HFS alone. In animals with unilateral dopamine lesion, a slight but significant increase was measured in the ipsilateral side, as previously reported (Vila et al., 1999), in the absence of contralateral change. This increase was totally abolished in animals with the lesion and STN HFS, mRNA levels measured in this condition being no more significantly different from controls 

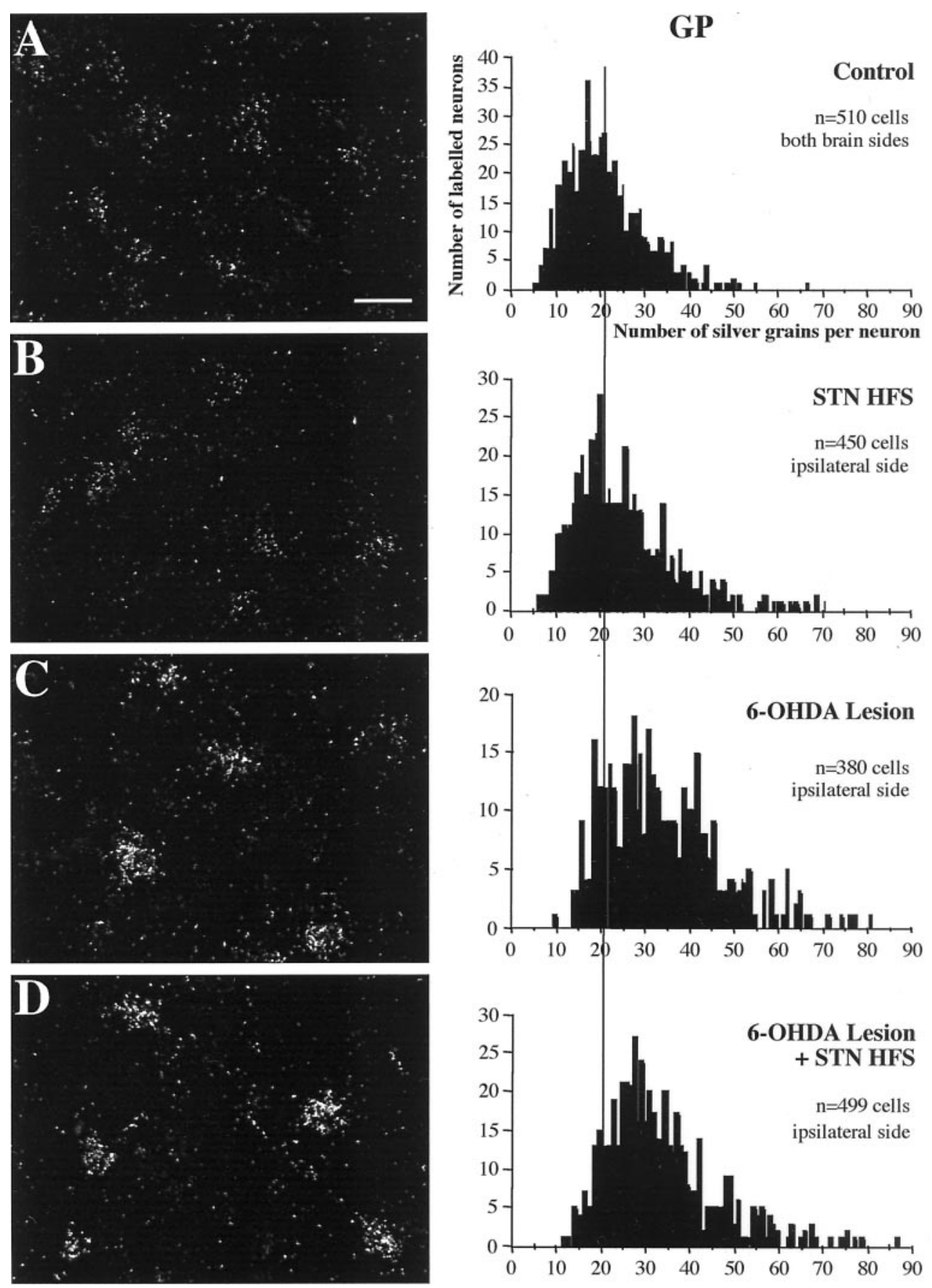

Figure 7. Photomicrographs taken under dark-field epi-illumination (left) and histograms of frequency distribution of labeling (right), illustrating the effects of highfrequency stimulation of the subthalamic nucleus and of 6-hydroxydopamine lesion of nigral dopamine neurons on GAD67 mRNA expression in the ipsilateral globus pallidus. Sections were processed for in situ hybridization with ${ }^{35}$ S-radiolabeled GAD67 oligoprobe and for emulsion autoradiography. Illustrations concern the following conditions: control $(A)$, stimulation alone $(B)$, dopamine lesion alone $(C)$, and dopamine lesion and subsequent stimulation $(D)$. Scale bar, $20 \mu \mathrm{m}$.

and significantly reduced $(-27 \%)$ compared with animals with the lesion alone. No change was observed in the contralateral SNr.

\section{DISCUSSION}

As a main finding, this study shows that STN HFS for a short duration decreases STN metabolic activity and is efficient in antagonizing cellular defects resulting from dopamine denervation in the output structures of the basal ganglia, $\mathrm{SNr}$ and $\mathrm{EP}$, but not in the striatum and GP. These data led to question the relative weight of STN contribution to the effects of dopamine lesion in the basal ganglia and/or the mechanisms of STN HFS.

STN HFS in normal monkey has been reported to induce dyskinesias contralateral to the stimulated STN (Beurrier et al., 1997), resembling human hemiballismus and those obtained in primates after STN lesion (Hamada and DeLong, 1992; Lee and Marsden, 1994). Accordingly, we report that unilateral STN HFS in intact rats can induce, depending on the stimulation intensity used, contralateral dyskinetic movements of the forepaw, contralateral bias, as observed after STN lesion (Henderson et al., 1999), and even contralateral rotational behavior. In addition, we observed that STN HFS in hemiparkinsonian rats can abolish the dopamine lesion-induced ipsilateral biases, but above a given threshold intensity, can also produce contralateral bias, dyskinetic movement, and rotation as observed in intact rats. This finding is consistent with previous reports showing that contralateral hemiballismus can occur after STN HFS in PD patients at a voltage higher than those producing antiparkinsonian benefits (Limousin 

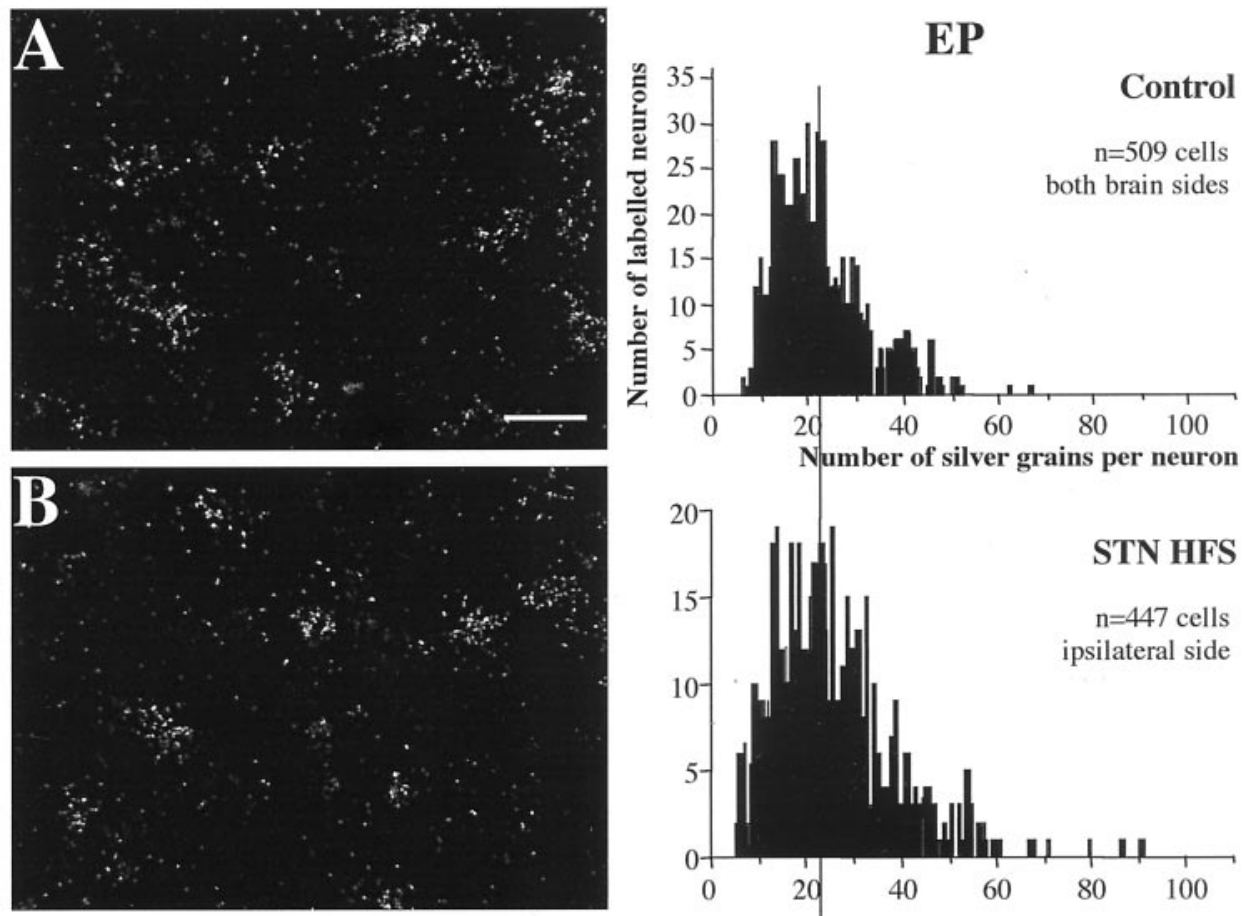

Figure 8. Photomicrographs taken under dark-field epi-illumination (left) and histograms of frequency distribution of labeling (right) illustrating the effects of highfrequency stimulation of the subthalamic nucleus and of 6-hydroxydopamine lesion of nigral dopamine neurons on GAD67 mRNA expression in the ipsilateral entopeduncular nucleus. Sections were processed for in situ hybridization with ${ }^{35}$ S-radiolabeled GAD67 oligoprobe and for emulsion autoradiography. Illustrations concern the following conditions: control $(A)$, stimulation alone $(B)$, dopamine lesion alone $(C)$, and dopamine lesion and subsequent stimulation $(D)$. Scale bar, $20 \mu \mathrm{m}$.
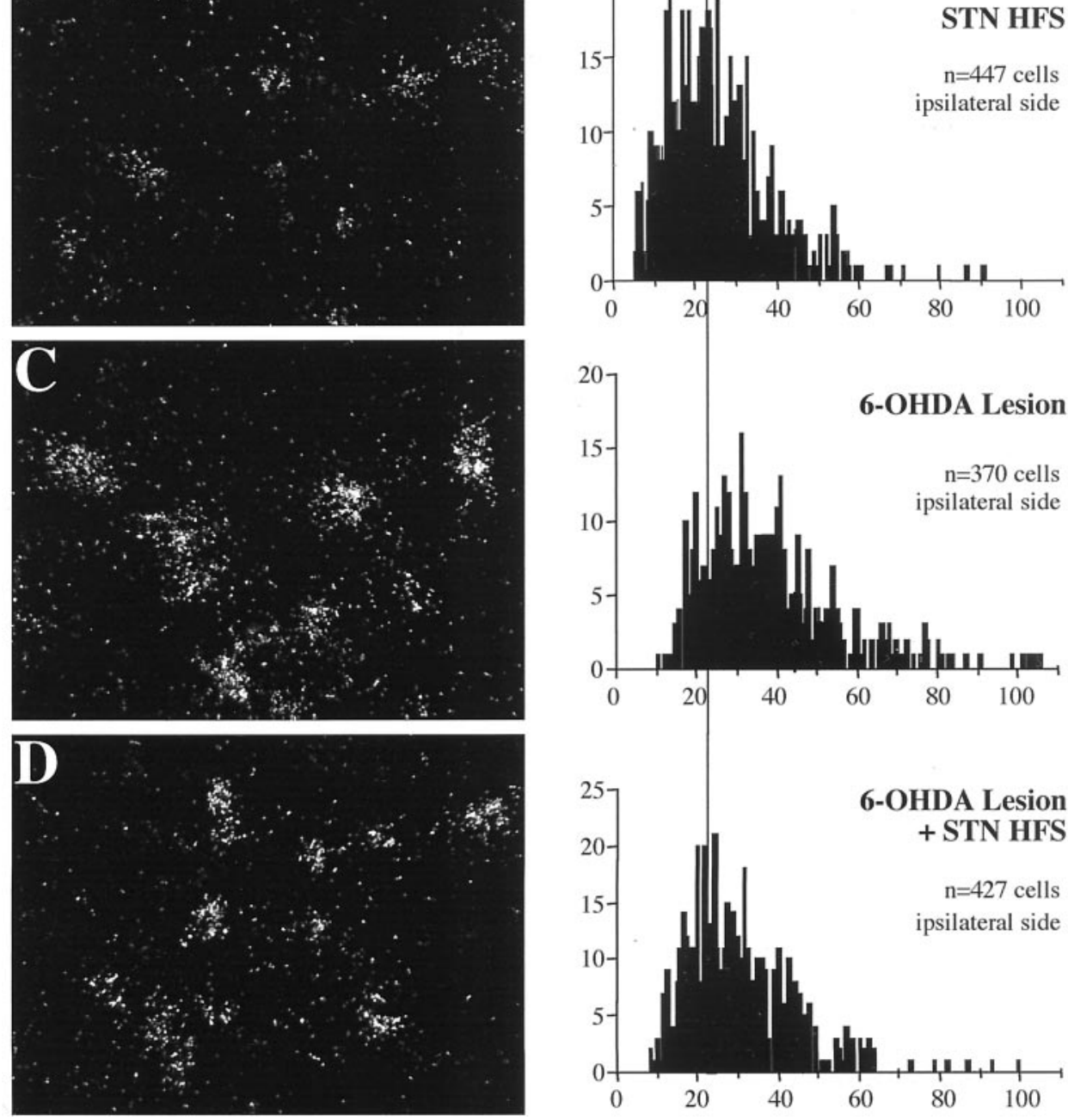

et al., 1996). Interestingly, however, we presently observed that higher intensity of stimulation was required to elicit dyskinesia in animals with the dopamine lesion compared with intact rats, evidencing increased threshold for the induction of dyskinesia by STN HFS in parkinsonian state, as previously suggested to be the case after STN lesioning (Guridi and Obeso, 2001). Because differential sensitivity to STN HFS appears as a feature of parkinsonian versus normal state, we therefore examined the cellular effects of this stimulation in intact and hemiparkinsonian rats using different intensities inducing similar behavioral effects in the two groups rather than identical intensity inducing different behavior.

Neuronal expression of immediate early genes act as indicators

of change in activity in neuronal systems (Hughes and Dragunow, 1995). CoI mRNA expression has been suggested to represent a marker of neuronal metabolic activity (Hirsch et al., 2000). STN HFS was shown here to induce expression of the immediate early gene product c-fos and to decrease CoI mRNA levels in STN neurons on the stimulation side in both intact rats and in animals with lesion of the nigral dopamine neurons on the same side. These changes testify of the efficiency of the stimulation procedure we used to modify STN activity, selectively, and suggest that STN HFS decreases STN neuron metabolic activity. This is in keeping with electrophysiological recordings showing that STN HFS in intact rats results in a decrease in activity of all STN cells 

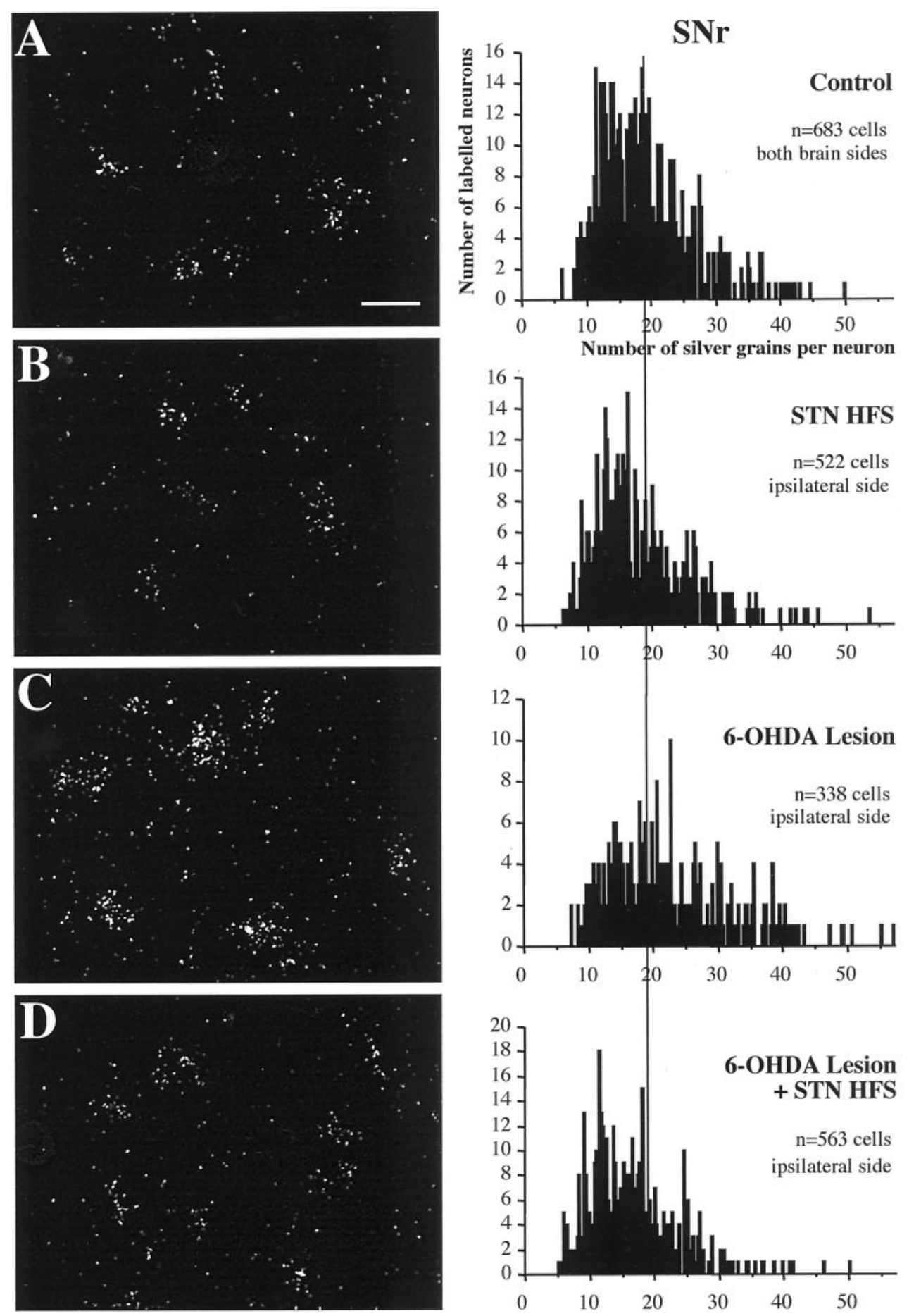

Figure 9. Photomicrographs taken under dark-field epi-illumination (left ) and histograms of frequency distribution of labeling (right) illustrating the effects of highfrequency stimulation of the subthalamic nucleus and of 6-hydroxydopamine lesion of nigral dopamine neurons on GAD67 mRNA expression in the ipsilateral substantia nigra pars reticulata. Sections were processed for in situ hybridization with ${ }^{35}$ S-radiolabeled GAD67 oligoprobe and for emulsion autoradiography. Illustrations concern the following conditions: control $(A)$, stimulation alone $(B)$, dopamine lesion alone $(C)$, and dopamine lesion and subsequent stimulation $(D)$. Scale bar, $20 \mu \mathrm{m}$.

recorded around the stimulation site in vivo (Benazzouz et al., 2000), although there is a controversy as to the mechanisms leading to reduced activity of these neurons, direct blockade of ongoing activities (Beurrier et al., 2001), and/or inhibition dependent on synaptic transmission (Grill and McIntyre, 2001). In our study, the dopamine lesion alone did not significantly affect $\mathrm{CoI}$ mRNA levels in the ipsilateral STN at 15-17 d after lesion, which disagrees with a previous report showing a slight but significant increase at $14 \mathrm{~d}$ after similar lesion (Vila et al., 2000). In the latter report, it was shown that changes in CoI mRNA expression is an early phenomenon preceding changes in electrical activity, and that changes were markedly reduced from $24 \mathrm{hr}$ to $14 \mathrm{~d}$ after 6-hydroxydopamine lesion. It then could be that the survival time examined is a turning point toward normalization and that the kinetic of this effect differs depending on the rat strains and/or extent of dopamine denervation. On the other hand, dopamine lesion alone induced a slight decrease in CoI mRNA levels in the contralateral STN, consistent with previous electrophysiological data emphasizing the importance of interhemispheric regulation of this structure (Mouroux et al., 1995; Perier et al., 2000). For instance, unilateral dopamine lesion has been reported to decrease neuron discharge rate in the contralateral STN, whereas increasing this rate in the ipsilateral STN (Perier et al., 2000). STN HFS in intact rats decreased bilaterally CoI mRNA levels in 

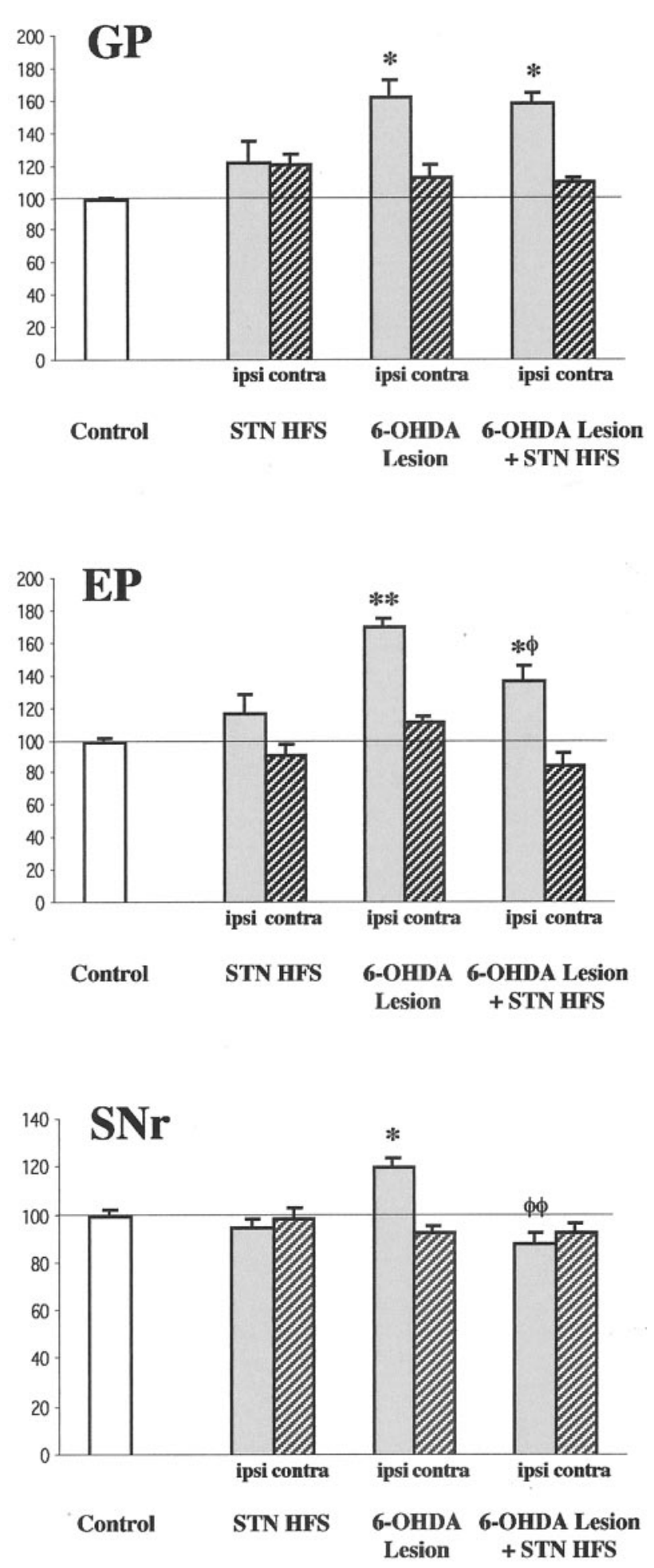

Figure 10. Quantitative analysis of the effects of high-frequency stimulation of the subthalamic nucleus and of 6-hydroxydopamine lesion of nigral dopamine neurons on the expression of GAD67 mRNA in the globus pallidus $(G P)$, entopeduncular nucleus $(E P)$, and substantia nigra pars reticulata $(S N r)$. The histograms represent the mean of silver grain number per labeled neuron on the side ipsilateral (ipsi) and contralateral (contra) to the lesion and/or stimulation. All data are expressed as percentage \pm SEM of the corresponding controls. Statistical comparisons are performed using a one-way ANOVA followed by Scheffé's test. * $p<$ 0.05 and ${ }^{* *} p<0.01$ compared with control values; ${ }^{\phi} p<0.05$ and ${ }^{\phi \phi} p<$ 0.01 compared with values obtained in animals with the dopamine lesion alone. the STN, although the contralateral effect was not significant. To our knowledge whether or not unilateral STN HFS affects contralateral STN neuron discharge rate is unknown. However, microdialysis studies in intact rats have shown bilateral changes in glutamate extracellular levels in STN targets after unilateral HFS (Windels et al., 2000). Interestingly, we did not observed additive effects of dopamine lesion and HFS, levels of CoI mRNA in the contralateral STN returning to control values in animals with combined dopamine lesion and STN HFS. This suggests an antagonistic interference between the effects of both types of surgery in the contralateral brain side. An interesting hypothesis is that unilateral STN HFS in animals with dopamine lesion on the same brain side may prevent the previously reported dopamine hyperactivity in the contralateral hemisphere (Nieoullon et al., 1977; Zhang et al., 1988).

STN HFS was found here to have no effect on neurotransmitter-related gene expression when applied in intact animals, whatever the basal ganglia structure examined, but to selectively antagonize some defects resulting from dopamine denervation in hemiparkinsonian rats. The lack of effect in intact animals cannot be attributed to the lower intensity of stimulation applied in this group compared with that used in hemiparkinsonian rats, because this stimulation was found to similarly decrease STN neuron metabolic activity and because STN lesion alone was previously reported to also have minimal effect in the basal ganglia (Delfs et al., 1995). Among the possible explanations, it could be that the influence of STN on neuronal metabolic activity in basal ganglia structures depends on the integrity of the dopamine system. This could be attributable to the functional inter-relationships between the STN and the nigral dopamine neurons as evidence has been provided that STN HFS in either intact rats or animals with partial dopamine lesion increases dopamine metabolism and transmission (Paul et al., 2000; Bruet et al., 2001) and conversely, that dopamine depletion modifies the firing pattern of STN neurons (Miller and Delong, 1987; Robledo and Feger, 1991; Hollerman and Grace, 1992; Bergman et al., 1994; Hassani et al., 1996; Kreiss et al., 1997; Ni et al., 2001). On the other hand, certain basal ganglia structures may be more sensitive to change in STN neuron activity in the parkinsonian versus normal state. In this connection, it has been reported that excitatory responses to pharmacological stimulation of the STN are potentiated in animals with monoamine depletion compared with controls in the $\mathrm{SNr}$ but not pallidum, further suggesting selective interactions between dopamine and STN afferents among basal ganglia structures (Robledo and Feger, 1991). Such selective interactions may also account for differential effects of STN surgery between basal ganglia structures in the parkinsonian state.

All the molecular effects of 6-hydroxydopamine-induced dopamine lesion described in this study at striatal, GP, and SNr level comply with previous reports by other groups (Gerfen et al., 1991; Kincaid et al., 1992; Soghomonian and Chesselet, 1992; Delfs at al., 1995; Vila et al., 1999). It is to note that an unexplained controversy persists in the literature as to the effects of dopamine lesion at EP level in rats, some studies reporting increased GAD67 mRNA levels in the EP ipsilateral to the lesion (Vila et al., 1999), as found here, whereas others show decreased GAD67 mRNA in the contralateral EP (Soghomonian and Chesselet, 1992; Delfs et al., 1995). In the primate 1-methyl-4-phenyl-1,2,3,6tetrahydropyridine (MPTP) model of PD, data concur to show increased GAD67 mRNA in the homologous GPi (Guridi et al., 1996; Herrero et al., 1996).

In hemiparkinsonian rats, STN HFS was found in the present 
study to antagonize the dopamine lesion-induced changes in GAD67 gene expression in the SNr, totally, and in EP, partially, but not in the GP and striatum. Reduction by STN HFS of the dopamine lesion-mediated increase in GAD67 mRNA levels in the output structures of the basal ganglia, SNr and EP, is consistent with the leading hypothesis that STN HFS, by blocking STN neuron activity, may reduce excitatory outputs from the STN. In keeping with this, the firing of $\mathrm{SNr}$ and $\mathrm{EP}$ neurons has been reported to be decreased after acute STN HFS (Benazzouz et al., 2000). Moreover, our data can be compared with a previous study in MPTP-treated primates showing that subthalamotomy reverses the dopamine lesion-mediated increase in GAD67 mRNA levels in SNr neurons (Guridi et al., 1996). The lack of effects on the changes in striatal enkephalin and substance P mRNA levels comply with the anatomical data showing that the dorsal striatum receives only sparse STN projections (Kita and Kitai, 1987). The inability of STN HFS to antagonize the dopamine lesion-mediated increase in GAD67 mRNA levels in the GP is puzzling since, the GP, like the $\mathrm{SNr}$ and $\mathrm{EP}$, represents a major target of STN projections (Kita and Kitai, 1987). If STN HFS simply reduces STN excitatory outflow, then the STN, at odd with the current view, would not have a pivotal role in mediating the dopamine lesion effects in the GP. In that case, the previously reported normalizing effects of STN lesion at GP level in rats with dopamine lesion (Delfs et al., 1995; Ni et al., 2000) may result from long-term adaptive mechanism, as suggested to be the case at striatal level (Delfs et al., 1995), rather than from direct removal of STN influence. Alternatively, STN inhibition may not be the only mechanism underlying the consequences of STN HFS on the functioning of basal ganglia structures. There is accumulating evidence that activation of other neurons or fiber tracts may contribute to the effects of HFS (Grill and McIntyre, 2001). For instance, acute STN HFS has been shown to not decrease but to increase GP neurons firing rate, contrary to that observed at $\mathrm{SNr}$ or EP level, presumably because of antidromic activation (Benazzouz et al., 1995). On the other hand, recent microdialysis data have shown that STN HFS does not affect significantly the dopamine lesion-mediated increase in extracellular glutamate levels in the $\mathrm{SNr}$ or GP, but selectively increases extracellular GABA levels in the SNr (Windels et al., 2001). Therefore, besides its impact on STN neurons and axons, which can be even different (Grill and McIntyre, 2001), STN HFS may affect GABA transmission in selected STN targets, which could account for the differential impact of STN HFS we found between the GP and the output structures of the basal ganglia.

In conclusion, our study shows that STN HFS can, in the short term, antagonize dopamine lesion-mediated change in gene expression in the output structures of the basal ganglia, providing the first molecular support to its beneficial effect on parkinsonian motor symptoms. Data further suggest a critical involvement of the $\mathrm{SNr}$ in the functional effects of this stimulation.

\section{REFERENCES}

Alvarez L, Macias R, Guridi J, Lopez G, Alvarez E, Maragoto C, Teijeiro J, Torres A, Pavon N, Rodriguez-Oroz MC, Ochoa L, Hetherington H, Juncos J, DeLong MR, Obeso JA (2001) Dorsal subthalamotomy for Parkinson's disease. Mov Disord 16:72-78.

Aziz TZ, Peggs D, Sambrook MA, Crossman AR (1991) Lesion of the subthalamic nucleus for the alleviation of 1-methyl-4-phenyl-1, 2, 3, 6-tetrahydropyridine (MPTP)-induced parkinsonism in the primate. Mov Disord 6:288-292.

Benabid AL, Pollak P, Louveau A, Henry S, De Rougemont J (1987) Combined (thalamotomy and stimulation) stereotaxic surgery of the VIM thalamic nucleus for bilateral Parkinson's disease. Appl Neurophysiol 50:344-346.

Benabid AL, Pollak P, Gervason C, Hoffmann D, Gao DM, Hommel M,
Perret J, De Rougemont J (1991) Long-term suppression of tremor by chronic stimulation of the ventral intermediate thalamic nucleus. Lancet 337:403-406.

Benabid AL, Krack PP, Benazzouz A, Limousin P, Koudsie A, Pollak P (2000) Deep brain stimulation of the subthalamic nucleus for Parkinson's disease: methodologic aspects and clinical criteria. Neurology 55:S40-44.

Benazzouz A, Gross C, Feger J, Boraud T, Bioulac B (1993) Reversal of rigidity and improvement in motor performance by subthalamic highfrequency stimulation in MPTP-treated monkeys. Eur J Neurosci 5:382-389.

Benazzouz A, Piallat B, Pollak P, Benabid AL (1995) Responses of substantia nigra pars reticulata and globus pallidus complex to high frequency stimulation of the subthalamic nucleus in rats: electrophysiological data. Neurosci Lett 189:77-80.

Benazzouz A, Gao DM, Ni ZG, Piallat B, Bouali-Benaouzzz R, Benabid AL (2000) Effect of high-frequency stimulation of the subthalamic nucleus on the neuronal activities of the substantia nigra pars reticulata and ventrolateral nucleus of the thalamus in the rat. Neuroscience 99:289-295.

Bergman H, Wichmann T, DeLong MR (1990) Reversal of experimental parkinsonism by lesions of the subthalamic nucleus. Science 249:1436-1438.

Bergman H, Wichmann T, Karmon B, DeLong MR (1994) The primate subthalamic nucleus. II Neuronal activity in the MPTP model of parkinsonism J Neurophysiol 72:507-520.

Beurrier C, Bezard E, Bioulac B, Gross C (1997) Subthalamic stimulation elicits hemiballismus in normal monkey. NeuroReport 8:16251629.

Beurrier C, Bioulac B, Audin J, Hammond C (2001) High-frequency stimulation produces a transient blockade of voltage-gated currents in subthalamic neurons. J Neurophysiol 85:1351-1356.

Blandini F, Garcia-Osuna M, Greenamyre JT (1997) Subthalamic ablation reverses changes in basal ganglia oxidative metabolism and motor response to apomorphine induced by nigrostriatal lesion in rats. Eur J Neurosci 9:1407-1413.

Bruet N, Windels F, Bertrand A, Feuerstein C, Poupard A, Savasta M (2001) High frequency stimulation of the subthalamic nucleus increases the extracellular contents of striatal dopamine in normal and partially dopaminergic denervated rats. J Neuropathol Exp Neurol 60:15-24.

Burbaud P, Gross C, Benazzouz A, Coussemacq M, Bioulac B (1995) Reduction of apomorphine-induced rotational behaviour by subthalamic lesion in 6-OHDA lesioned rats is associated with a normalization of firing rate and discharge pattern of pars reticulata neurons. Exp Brain Res 105:48-58.

Delfs JM, Ciaramitaro VM, Parry TJ, Chesselet MF (1995) Subthalamic nucleus lesions: widespread effects on changes in gene expression induced by nigrostriatal dopamine depletion in rats. J Neurosci 15:6562-6575.

Gerfen CR, McGinty JF, Young WS 3rd (1991) Dopamine differentially regulates dynorphin, substance $\mathrm{P}$, enkephalin expression in striatal neurons: in situ hybridization histochemical analysis. J Neurosci 11:1016-1031.

Grill WM, McIntyre CC (2001) Extracellular excitation of central neurons: implications for the mechanisms of deep brain stimulation. Thalamus and Related Systems 1:269-277.

Guridi J, Obeso JA (2001) The subthalamic nucleus, hemiballismus and Parkinson's disease: reappraisal of a neurosurgical dogma. Brain 124:5-19.

Guridi J, Herrero MT, Luquin MR, Guillen J, Ruberg M, Laguna J, Vila M, Javoy-Agid F, Agid Y, Hirsch E, Obeso JA (1996) Subthalamotomy in parkinsonian monkeys. Behavioral and biochemical analysis. Brain 119:1717-1727.

Hamada I, DeLong MR (1992) Excitotoxic acid lesions of the primate subthalamic nucleus result in transient dyskinesias of the contralateral limbs. J Neurophysiol 68:1850-1858.

Hajji MD, Salin P, Kerkerian-Le Goff L (1996) Chronic dizocilpine maleate (MK-801) treatment suppresses the effects of nigrostriatal dopamine deafferentation on enkephalin but not on substance P expression in the rat striatum. Eur J Neurosci 8:917-926.

Hassani OK, Mouroux M, Feger J (1996) Increased subthalamic neuronal activity after nigral dopaminergic lesion independent of disinhibition via the globus pallidus. Neuroscience 72:105-115.

Henderson JM, Annett LE, Ryan LJ, Chiang W, Hidaka S, Torres EM Dunnett SB (1999) Subthalamic nucleus lesions induce deficits as well as benefits in the hemiparkinsonian rat. Eur J Neurosci 11:2749-2757.

Herrero MT, Levy R, Ruberg M, Luquin MR, Villares J, Guillen J, Faucheux B, Javoy-Agid F, Guridi J, Agid Y, Obeso JA, Hirsch EC (1996) Consequence of nigrostriatal denervation and L-dopa therapy on the expression of glutamic acid decarboxylase messenger RNA in the pallidum. Neurology 47:219-224.

Hirsch EC, Perier C, Orieux G, François C, Feger J, Yelnik J, Vila M, Levy R, Tolosa ES, Marin C, Herrero MT, Obeso JA, Agid Y (2000) 
Metabolic effects of nigrostriatal denervation in basal ganglia. Trends Neurosci 23:S78-S85.

Hollerman JR, Grace AA (1992) Subthalamic nucleus cell firing in the 6-OHDA treated rat: basal activity and response to haloperidol. Brain Res 590:291-299.

Hughes PE, Dragunow M (1995) Induction of immediate-early genes and the control of neurotransmitter-regulated gene expression within the nervous system. Pharmacol Rev 47:133-178.

Kincaid AE, Albin RL, Newman SW, Penney JB, Young AB (1992) 6-hydroxydopamine lesions of the nigrostriatal pathway alter the expression of glutamate decarboxylase messenger RNA in the rat globus pallidus projection neurons. Neuroscience 51:705-718.

Kita H, Kitai ST (1987) Efferent projections of the subthalamic nucleus in the rat: Light and electron microscopic analysis with the PHA-L method. J Comp Neurol 260:435-452.

Krause M, Fogel W, Heck A, Hacke W, Bonsanto M, Trenkwalder C, Tronnier V (2001) Deep brain stimulation for the treatment of Parkinson's disease: subthalamic nucleus versus globus pallidus internus. J Neurol Neurosurg Psychiatry 70:464-470.

Kreiss DS, Mastropietro CW, Rawji SS, Walters JR (1997) The response of subthalamic nucleus neurons to dopamine receptor stimulation in a rodent model of Parkinson's disease, J Neurosci 17:6807-6819.

Lee MS, Marsden CD (1994) Movement disorders following lesions of the thalamus or subthalamic region. Mov Disord 9:493-507.

Liévens JC, Dutertre M, Forni C, Salin P, Kerkerian-Le Goff L (1997) Continuous administration of the glutamate uptake inhibitor L-transpyrrolidine-2, 4-dicarboxylate produces striatal lesion. Mol Brain Res 50:181-189.

Limousin P, Pollak P, Benazzouz A, Hoffmann D, Broussolle E, Perret JE, Benabid AL (1995) Bilateral subthalamic nucleus stimulation for severe Parkinson's disease. Mov Disord 10:672-674.

Limousin P, Hoffmann D, Benazzouz A, Perret JE, Benabid AL (1996) Abnormal involuntary movements induced by subthalamic nucleus stimulation in parkinsonian patients. Mov Disord 1:231-235.

Miller WC, DeLong MR (1987) Altered tonic activity of neurons in the globus pallidus and subthalamic nucleus in the primate MPTP model of parkinsonism. In: The basal ganglia II (Carpenter MB, Jayaraman A, eds), pp 415-427. New York: Plenum.

Mouroux M, Hassani OK, Feger J (1995) Electrophysiological study of the excitatory parafascicular projection to the subthalamic nucleus and evidence for ipsi- and contralateral controls. Neuroscience 67:399-407.

Nieoullon A, Cheramy A, Glowinski J (1977) Interdependence of the nigrostriatal dopaminergic systems on the two sides of the brain in the cat. Science 198:416-418.

Ni Z, Bouali-Benaouzzz R, Gao D, Benabid AL, Benazzouz A (2000) Changes in the firing pattern of globus pallidus neurons after the degeneration of nigrostriatal pathway are mediated by the subthalamic nucleus in the rat. Eur J Neurosci 12:4338-4344.

Ni Z, Bouali-Benaouzzz R, Gao D, Benabid A, Benazzouz A (2001) Time-course of changes in firing rates and firing patterns of subthalamic nucleus neuronal activity after 6-OHDA-induced dopamine depletion in rats. Brain Res 899:142-147.

Paul G, Reum T, Meissner W, Marburger A, Sohr R, Morgenstern R, Kupsch A (2000) High frequency stimulation of the subthalamic nucleus influences striatal dopaminergic metabolism in the naive rat NeuroReport 11:441-444.

Paxinos G, Watson C (1986) The rat brain in stereotaxic coordinates. New York: Academic.

Perier C, Agid Y, Hirsch EC, Feger J (2000) Ipsilateral and contralateral subthalamic activity after unilateral dopaminergic lesion. NeuroReport 11:3275-3278.

Pollak P, Benabid AL, Gross C, Gao DM, Laurent A, Benazzouz A, Hoffmann D, Gentil M, Perret J (1993) Effects of the stimulation of the subthalamic nucleus in Parkinson's disease. Rev Neurol (Paris) 149:175-176.

Robledo P, Feger J (1991) Acute monoaminergic depletion in the rat potentiates the excitatory effect of the subthalamic nucleus in the substantia nigra pars reticulata but not in the pallidal complex. J Neural Transm Gen Sect 86:115-126.

Salin P, Hajji MD, Kerkerian-Le Goff L (1996) Bilateral 6-hydroxydopamine-induced lesion of the nigrostriatal dopamine pathway reproduces the effects of unilateral lesion on substance P but not on enkephalin expression in rat basal ganglia. Eur J Neurosci 8:1746-1757.

Soghomonian JJ, Chesselet MF (1992) Effects of nigrostriatal lesions on the levels of messenger RNAs encoding two isoforms of glutamate decarboxylase in the globus pallidus and entopeduncular nucleus of the rat. Synapse 11:124-133.

Vila M, Marin C, Ruberg M, Jimenez A, Raisman-Vozari R, Agid Y Tolosa E, Hirsch E (1999) Systemic administration of NMDA and AMPA receptor antagonists reverses the neurochemical changes induced by nigrostriatal denervation in basal ganglia. J Neurochem 73:344-352.

Vila M, Perier C, Feger J, Yelnik J, Faucheux B, Ruberg M, RaismanVozari R, Agid Y, Hirsch EC (2000) Evolution of changes in neuronal activity in the subthalamic nucleus of rats with unilateral lesion of the substantia nigra assessed by metabolic and electrophysiological measurements. Eur J Neurosci 12:337-344.

Windels F, Bruet N, Poupard A, Urbain N, Chouvet G, Feuerstein C, Savasta M (2000) Effects of high frequency stimulation of subthalamic nucleus on extracellular glutamate and GABA in substantia nigra and globus pallidus in the normal rat. Eur J Neurosci 12:4141-4146.

Windels F, Bruet N, Poupard A, Feuerstein C, Bertrand A, Savasta M (2001) Evidence for a possible role of GABA in the therapeutical efficacy of high frequency stimulation of the subthalamic nucleus in Parkinson's disease: a microdialysis study in rats. Soc Neurosci Abstr 966.10.

Zhang WQ, Tilson HA, Nanry KP, Hudson PM, Hong JS, Stachowiak MK (1988) Increased dopamine release from striata of rats after unilateral nigrostriatal bundle damage. Brain Res 461:335-342. 